\title{
Hand Hygiene Compliance in the Prevention of Nosocomial Infections in the Neonatal Unit of the National University Teaching Hospital of Cotonou
}

\author{
Marcelline d'Almeida1 ${ }^{*}$, Lehila Bagnan', Silé Souam Nguele ${ }^{2}$, Edwige Djagoun1, \\ Edgard Marius Ouendo ${ }^{3}$, Blaise Ayivi' ${ }^{1}$, Nicole Bouali Rouvinez ${ }^{4}$ \\ ${ }^{1}$ Neonatal Unit, Department of Mother and Child, National University Teaching Hospital, Cotonou, Benin \\ ${ }^{2}$ Pediatric Unit, Mother and Child Hospital, Ndjamena, Chad \\ ${ }^{3}$ Regional Institute of Public Health, University of Abomey-Calavi, Ouidah, Benin \\ ${ }^{4}$ University of Ottawa, Ottawa, Canada \\ Email: *dalmeidine@yahoo.fr
}

How to cite this paper: d'Almeida, M., Bagnan, L., Nguele, S.S., Djagoun, E., Ouendo, E.M., Ayivi, B. and Rouvinez, N.B. (2017) Hand Hygiene Compliance in the Prevention of Nosocomial Infections in the Neonatal Unit of the National University Teaching Hospital of Cotonou. Open Journal of Pediatrics, 7, 282-288.

https://doi.org/10.4236/ojped.2017.74032

Received: September 22, 2017

Accepted: November 18, 2017

Published: November 21, 2017

Copyright $\odot 2017$ by authors and Scientific Research Publishing Inc. This work is licensed under the Creative Commons Attribution International License (CC BY 4.0).

http://creativecommons.org/licenses/by/4.0/

\begin{abstract}
Objective: Despite the presence of hand washing material and the training given to medical staff regarding hygiene measures and health care procedures in October 2015, the prevalence of nosocomial infections in the neonatal unit of the National University Teaching Hospital of Cotonou (CNHU-Cotonou) was estimated at $8 \%$ in January 2016 . To determine the factors that contribute to these infections, this study assessed medical staff compliance with hand hygiene measures and procedures. Method: This research was a cross-sectional and observational study conducted from February 15 to March 31, 2016 through direct and cautious observation of 47 members of the medical and paramedical staff. The study variables were hand washing before entering the neonatal unit and before entering each treatment room, hand washing before and after seeing each patient, compliance with hand washing steps, the use of hydroalcoholic solutions and adhering to the ban on mobile phone use inside the treatment room. Results: Only 15\% of the medical staff followed all of the rules and measures governing hand hygiene. The result showed that $76.6 \%$ of them did not wash their hands before entering the unit; $32 \%$ washed their hands before each care session; $95.7 \%$ washed their hands after each care session; and $85 \%$ did not comply with the hand washing steps. Only $21.3 \%$ of the personnel used hydroalcoholic solution, and only $85 \%$ of the personnel adhered to the ban on mobile phone use within the treatment room. Conclusion: Compliance with hand hygiene measures is insufficient. These low compliance rates
\end{abstract}


facilitate the occurrence of nosocomial infections. Nosocomial infections could be prevented by identifying the reasons that medical personnel do not wash their hands and by implementing a program for education/awareness on hygiene measures based on an analysis of errors and care procedures and sustained by regular evaluations.

\section{Keywords}

Hand Washing, Nosocomial Infection, Neonatal Unit, Cotonou, Benin

\section{Introduction}

Because of their severity and high costs, nosocomial or health facility-acquired infections are a major health issue concerning newborns, especially premature infants [1]. The infectious agents involved are generally resistant to usual antibiotics, change overtime and vary between healthcare units. The infections cause intermittent outbreaks and high lethality when they colonize a health facility [2]. These nosocomial infections are facilitated by several procedures. Medical staff's contaminated hands, resulting from poor hand hygiene, are the most common transmission pathway for pathogens in most health facilities [3]. After the renovation and extension of the neonatal unit of CNHU-Cotonou, hand washing stations were installed at the entrance of the unit and inside all treatment rooms. Moreover, the medical and paramedical staff was trained on hygiene measures in health care in October 2015. The identification of severe sepsis associated with Klebsiella pneumoniae in some infants in the unit was associated with a nosocomial infection prevalence of $8 \%$ in January 2016 [4]. In a search for contributing factors, this study was undertaken in order to assess medical staff adherence to hand hygiene measures.

\section{Study Setting and Method}

\subsection{Study Setting}

The study was conducted in the neonatal unit of CNHU-Cotonou; this unit is a ward with a capacity of 50 cradles and incubators and is divided into two sectors. One sector is dedicated to preterm newborns, and the other is for full-term infants. Each sector consists of separate rooms for children born in the CNHU maternity ward and children born outside of CNHU. Care in the neonatal unit is provided to infants in vital distress who need intensive care, to sick infants and to preterm infants who benefit from incubators, which provide optimal conditions for their growth and development. Additionally, care is given to healthy infants awaiting their mother's discharge from the intensive care unit. The neonatal unit provides care to an average of 3000 newborns per year. In this unit, each room is equipped with hand washing stations including a washbasin, fluid soap and hand towels. Bottles containing hydroalcoholic solutions are also hung on each cradle. The 
materials and cloths are sterilized using Poupinel and the sanitation of floor, windows and doors is ensured everyday by a qualified cleaning company. Finally, mobile phone use is prohibited in the treatment rooms.

\subsection{Method}

This research was a cross-sectional descriptive and observational study carried out from February 15 to March 31, 2016. The study focused on hand hygiene compliance in healthcare using a grid and through direct and cautious observation of all medical and paramedical personnel working in the unit. The observations were made without the personnels' knowledge, starting from the time they entered the unit.

The observations were centered on the care procedures performed by a trainee attending the academic program leading to the degree of advanced specialization studies in pediatrics, whose assignment was unknown.

Since the recruitment was exhaustive, the sample size was not calculated and takes into account all the nursing staff of the unit in operation during the study period. The total number of the medical and paramedical personnel who were under observation was 47.

The study variables were as follows: hand washing before entering the unit and each treatment room, hand washing before and after care, compliance with hand washing steps, use of hydroalcoholic solutions and adherence to the ban on mobile phone use in treatment rooms.

The hand washing steps to be followed were based on WHO recommendations [5]. They suggest the following:

1) Remove wrist bands, rings and watches, which are very difficult to clean,

2) Wet hands and forearms,

3) Apply a dose of soft soap or disinfectant evenly on hands,

4) Rub hands, palms, back of hands, interdigital spaces, fingertips, nail contours and wrists for 5 seconds each,

5) Rinse thoroughly with water, from fingertips toward wrists,

6) Dry hands with a single use towel,

7) Turn off the tap with the towel and throw it away without touching the trashcan.

Hand washing should last 40 to 60 seconds.

This study was submitted to the administrative authorities and to hygiene committee of CNHU-Cotonou and obtained their approval.

\section{Results}

The nursing staff at the time of the study was 47 , divided into 26 Nurses, 13 Assistant nurses, 4 Pediatricians and 4 Medical doctors in training for the degree of advanced studies with specialization in pediatrics. The number and roles of the medical and paramedical personnel are specified in Table 1.

Only 7 (15\%) of the medical staff complied with all of the hand hygiene measures. 
Table 1. Distribution of the medical staff of the neonatal unit of CNHU-Cotonou in 2016.

\begin{tabular}{ccc}
\hline Staff & Numbers & $\%$ \\
\hline Nurses & 26 & 55.4 \\
Assistant nurses & 13 & 27.6 \\
Pediatricians & 04 & 8.5 \\
Medical doctors in training for the degree of advanced & 04 & 8.5 \\
studies with specialization in pediatrics & & 100 \\
\hline TOTAL & 47 & \\
\hline
\end{tabular}

Table 2. Distribution of 47 members of the medical staff according to hand hygiene compliance.

\begin{tabular}{|c|c|c|c|}
\hline & & Numbers & $\%$ \\
\hline \multirow{2}{*}{ Hand washing before e } & Yes & 11 & 23.4 \\
\hline & No & 36 & 76.6 \\
\hline \multirow{2}{*}{ Hand washing before se } & Yes & 15 & 32 \\
\hline & No & 32 & 68 \\
\hline \multirow{2}{*}{ Hand washing after see } & Yes & 45 & 95.7 \\
\hline & No & 2 & 4.3 \\
\hline \multirow{2}{*}{ Compliance with hand } & Yes & 7 & 15 \\
\hline & No & 40 & 85 \\
\hline \multirow{2}{*}{ Use of hydroalcoho } & Yes & 10 & 21.3 \\
\hline & No & 37 & 78.7 \\
\hline \multirow{2}{*}{ Mobile phone use in $\mathrm{tr}$} & Yes & 40 & 85 \\
\hline & No & 7 & 15 \\
\hline Total & & 47 & 100 \\
\hline
\end{tabular}

Table 2 summarizes the results of staff adherence to hand hygiene measures in the CNHU's neonatal intensive care unit.

\section{Discussion}

The evaluation of compliance with hand hygiene measures in the neonatal unit of CNHU-Cotonou has noted that only 7 (15\%) of the personnel put into practice all of the hospital hygiene measures. The study found that $36(76.6 \%)$ of the personnel did not their wash hands before entering the unit; only $15(32 \%)$ of them washed their hands before patient care. Moreover, 45 (95.7\%) washed their hands after patient care, and 40 (85\%) did not comply with hand washing steps. Like at CNHU of Cotonou, other researchers has found the same results and have demonstrated that hand hygiene techniques remain poorly or incorrectly complied with by medical personnel [6] [7] [8]. At the unit of neonatology and intensive care of the service of infant medicine and neonatology of hospital Nord, Marseille, Dicko-Traore found that near the quarter of the staff (23.6\%) think 
that the hydro-alcoholic solutions are less effective than the simple hand washing. In respectively $20 \%$ and $36 \%$ of the cases, the staff underestimates the duration of the hand washing procedure and the hydro-alcoholic friction [6]. Research work carried out in Ghana found that only $21.1 \%$ of the medical practitioners implemented hand hygiene measures before contact with patients [7]. Another study conducted in France found health personnel's hand hygiene compliance to be estimated at $52.9 \%$ [8].

The implementation of a program for education/awareness on hand washing has enabled hospitals to significantly reduce the nosocomial infection rate [9]. Contrary to what some staff members claimed, systematic hand disinfection is not a waste of time that extends work, especially when the number of nurses is insufficient for the workload [9].

Should the ban on mobile phone use be maintained in the neonatal unit of CNHU-Cotonou? There is no doubt about it, for the excessive use of this communication tool distracts from adequate administration of care and represents a vector for pathogen transmission.

Hand washing, which is a very inexpensive operation, remains the lynchpin in the prevention of bacterial and viral nosocomial infections. Its effectiveness is guaranteed, provided that the majority of the personnel are provided training and implements it adequately [9].

At CNHU of Cotonou, only 15\% of the personnel complied with hand washing steps in March 2016 despite their training in October 2015. This result should induce the unit management to identify mechanisms to motivate the personnel to focus on hand hygiene, perform periodical evaluations of staff hand washing and review hand-washing techniques with the personnel whenever required.

Through a review of the literature on the factors influencing hand washing staff adherence, Mallaret et al. reported that if the level of lavatory equipment is significant, the motivation and evaluation of the staff are more important. The impact of the training is positive if it includes an active approach with analysis of errors and gestures of care and if it is maintained by regular evaluations with repeated return of the results to the services evaluated [10].

Effective times for hand washing in health care units are before touching the patient, before an aseptic procedure, after a risk for exposure to a biological fluid, after touching a patient and after touching a patient's environment [5].

In addition to conventional washing, the use of hydroalcoholic solutions plays an important role in hand disinfection. Alcohol-based hand rub is as effective as hand washing with soap and water [11]. It is an alternative solution that is recommended because of its effectiveness on pathogens and its affordable cost; it is also easy to use [12] [13].

\section{Conclusion}

The evaluation of hand hygiene compliance by the medical personnel of the neonatal unit of CNHU-Cotonou in March 2016 found adherence to the main hygiene 
measures by only $15 \%$ of the staff. Before entering treatment rooms, $23.4 \%$ of the personnel washed their hands, $32 \%$ before each seeing a patient, and only $15 \%$ adhered to hand washing steps, despite a previous training on hygiene measures in health care. These low compliance rates facilitate the occurrence of nosocomial infections, which could be prevented by identifying the reasons why most members of the medical staff do not wash their hands. Therefore, faced with this situation, it is necessary to repeat the hand washing technique with the personnel on a regular basis. This means implementing a program for education and awareness of hygiene measures, based on the analysis of errors and care procedures, which is sustained by regular evaluations.

\section{References}

[1] Garner, J.S., Jarvis, W.R. and Emori, T.G. (1988) CDC Definitions for Nosocomial Infections, 1988. American Journal of Infection Control, 16, 128-140. https://doi.org/10.1016/0196-6553(88)90053-3

[2] El Rhazi, K., Elfakir, S., Berraho, M., Tachfouti, N., Serhier, Z. and Kanjaa, C. (2007) Prevalence and Risk Factors for Nosocomial Infections in the Hassan II Teaching Hospital of Fes (Morocco). Revue de Santé de la Méditerranée Orientale, 13, 56-63.

[3] Branger, B. (2001) National Survey on Nosocomial Infection Prevalence in Infants, Children and Adolescents under 18 Years of Age. Archives de Pédiatrie, 12, 1085-1093. https://doi.org/10.1016/j.arcped.2005.02.011

[4] d'Almeida, M., Bagnan L., Silé, S.N., Djagoun, E., Ouendo, E.M., Ayivi, B., et al. (2017) Nosocomial Infections. Case-Control Study of 45 Cases at the Neonatal Unit of CNHU of Cotonou. Journal Africain de Pédiatrie et de Génétique Médicale, 2, 20-25.

[5] WHO (2010) WHO Guidelines on Hand Hygiene in Health Care: A Summary, Geneva $2010 \mathrm{WHO} / \mathrm{IER} / \mathrm{PSP} / 2009.07$. http://www.who.int/gpsc/5may/tools/9789241597906/en/

[6] Dicko-Traore, F., Gire, C., Brevaut Malaty, V., Busutill, M., Monnier, A.S. and Brunel, V. (2011) Evaluation of Hand Hygiene Knowledge and Practices in the Neonatal and Intensive Care Unit of the Child and Infant Department, North Hospital, Marseille. Journal de Pédiatrie et de Puériculture, 24, 172-177.

[7] Asare, A., Enweronu-Laryea, C.C. and Newman, M.J. (2009) Hand Hygiene Practices in A neonatal Intensive Care Unit in Ghana. Journal of Infection in Developing Countries, 3, 352-356.

[8] Raymond, F., Guilloteau, V., Pradelle, M.T., Jammes, M.M., Joly-Guillou, M.L., Brunel, P., et al. (2009) Evaluation of Compliance with Hand Hygiene and Associated Practices in Four Health Facilities of the Maine-et-Loire Region Participating to an Anti-Nosocomial Infection Network. Hygiène, XVII, 385-391.

[9] Aujard, Y., Bedu, A., Bingen, E. and Bonacorsi, S. (1995) Pediatic Nosocomial Infections. Médecine et Maladies Infectieuses, 25, 36-43. https://doi.org/10.1016/S0399-077X(05)80671-7

[10] Mallaret, M.R., Le Coz Iffenecker, A., Luu Duc, D., Brut, A., Veyre, M., Chaize, P., et al. (1998) Observance of Hand Washing in Hospitals: Analysis of the Literature. Médecine et Maladies Infectieuses, 28, 285-290. https://doi.org/10.1016/S0399-077X(98)80051-6

[11] Girou, E. (2006) Simplification of Hygiene Measures in the Prevention of Nosocomial Infections. Réanimation, 15, 195-197. 
[12] Maury, E. and Offenstadt, G. (2002) Importance of Hydroalcoholic Solutions in Intensive Care. Réanimation, 11, 186-192.

https://doi.org/10.1016/S1624-0693(02)00230-X

[13] Boyce, J.M. and Pittet, D. (2002) Health Care Infection Control Practices Advisory Committee; HICPAC/SHEA/APIC/IDSA Hand Hygiene Task Force. Guidelines for Hand Hygiene in Health-Care Settings. Recommendations of the Healthcare Infection Control Practices Advisory Committee and the HICPAC/SHEA/APIC/IDSA Hand Hygiene Task Force. Society for Healthcare Epidemiology of America/Association for Professionals in Infection Control/Infectious Diseases Society of America. MMWR Recommendations and Reports, 51, 1-45. 